\title{
PROJETO INTERDISCIPLINAR: DESENVOLVIMENTO DE COMPETÊNCIAS TRANSVERSAIS
}

Sandra Regina Chalela Ayub ${ }^{1}$, Raul Aragão Martins².

${ }^{1}$ Doutoranda em Educação pela Universidade Estadual Paulista - UNESP/Marília, Professora da Fatec Catanduva. E-mail: sandrachalela@gmail.com

${ }^{2}$ Livre-Docente em Psicologia da Educação pela Universidade Estadual Paulista - UNESP, Professor adjunto do Departamento de Educação do Instituto de Biociências, Letras e Ciências Exatas - IBILCE, da Universidade Estadual Paulista - UNESP, São José do Rio Preto, SP e do Programa de Pós-Graduação em Educação da Universidade Estadual Paulista - UNESP, Marília, SP.

\section{RESUMO}

Muitos profissionais graduados não conseguem adentrar no mercado de trabalho. Possivelmente, as competências específicas desenvolvidas na graduação não foram suficientes para torná-los competitivos. Necessita-se que as Instituições de Ensino Superior desenvolvam estratégias educacionais, proporcionando desenvolvimento holístico, com visão integradora das competências e, consequentemente, do desenvolvimento de competências transversais - conhecimentos, habilidades, atitudes que um indivíduo pode mobilizar para desempenho de diferentes atividades profissionais, proporcionando elo entre o conhecimento técnico e o mercado na prática. Assim, esta pesquisa teve por objetivo analisar as competências transversais desenvolvidas nos alunos do curso de Tecnologia em Gestão Empresarial por meio do Projeto Interdisciplinar da FATEC Catanduva. Realizou-se pesquisa exploratória e de campo aplicando Inventário de Habilidades Discentes em 227 estudantes, analisando 5 competências transversais. Verificou-se que o Projeto Interdisciplinar desenvolve todas as competências transversais avaliadas, possibilitando o aluno aplicar conhecimentos técnicos na prática do mercado de trabalho.

Palavras-chave: Competência Profissional. Prática Interdisciplinar. Ensino. Avaliação do Ensino. Avaliação da Educação.

\section{INTERDISCIPLINARY PROJECT: DEVELOPMENT TRANSVERSAL COMPETENCIES.}

\begin{abstract}
Many graduates are unable to enter the job market. Possibly, the competencies acquired during graduation are not enough to make them competitive. Higher Education Institutions are required to develop educational skills, providing holistic development, with the integrative view of competencies and, consequently, the development of transversal competencies - knowledge, skills, attitudes that an individual can put together to perform different professional tasks, providing the link between technical knowledge and the professional practice. Thus, the aim of this research was to analyze the transversal competencies developed by the students attending the Technology in Business Management Course, through an Interdisciplinary Project. An exploratory and field research was carried out by applying the Inventory of Student Skills in 227 students, analyzing 5 transversal competencies. The Interdisciplinary Project was confirmed to develop all transversal competencies analyze, allowing students to put technical knowledge in practice in the job market.
\end{abstract}

Keywords: Professional Competence. Interdisciplinary Placement. Teaching. Evaluation of Teaching. Education Measurement.

\section{PROYECTO INTERDISCIPLINARIO: DESARROLLO DE COMPETENCIAS TRANSVERSALES}

\section{RESUMEN}

Muchos profesionales graduados no logran entrar en el mercado de trabajo. Posiblemente, las competencias específicas desarrolladas en la graduación no fueron suficientes para hacerlos competitivos. Se necesita que las instituciones de enseñanza superior desarrollen estrategias educativas, proporcionando desarrollo holístico, con visión integradora de las competencias y, consecuentemente, del desarrollo de 
competencias transversales - conocimientos, habilidades, actitudes que un individuo puede poner en acción para desempeño de diferentes actividades profesionales, proporcionando una conexión entre el conocimiento técnico y el mercado en la práctica. Así, el objetivo de esta investigación fue analizar las competencias transversales desarrolladas en los alumnos de la carrera de Tecnología en Gestión Empresarial a través del Proyecto Interdisciplinario de la FATEC Catanduva. Se realizó investigación exploratoria y de campo aplicando Inventario de Habilidades Discentes en 227 estudiantes, analizando 5 competencias transversales. Se verificó que el Proyecto Interdisciplinario desarrolla todas las competencias transversales evaluadas, posibilitando que el alumno aplique conocimientos técnicos en la práctica del mercado de trabajo.

Palabras clave: Competencia Profesional. Práctica Interdisciplinaria. Educación. Evaluación de la Enseñanza. Evaluación de la Educación.

\section{INTRODUÇÃO}

Todos os anos muitos jovens graduam-se no ensino superior passando a enfrentar o desafio de se colocarem ativamente no mercado de trabalho, e infelizmente percebe-se que uma parte considerável deles, em pouco tempo, acaba se "encaixando" em alguma área diferente daquela na qual se formou ou ficam paralisados frente aos diversos desafios.

Segundo Mansilha (2012, p. 9), esse desencontro ocorre pela "falta de alinhamento entre aquilo que se aprende na universidade e aquilo que se busca na 'vida real'". A competitividade no mundo das organizações exige profissionais competentes em diversas áreas do que somente na qual se graduou. Muitos não conseguem transformar 0 conhecimento e habilidades adquiridas em algo que traga algum retorno efetivo profissional e/ou pessoal. Essa situação ocorre, segundo o autor, pois as competências específicas que aprenderam na graduação não são suficientes para torná-los competitivos. Necessitando, assim, desenvolver competências transversais que proporcionam suporte e elo entre o conhecimento técnico e o mercado na prática.

O conceito de competência não é recente, porém (re-)conceituada e (re-)valorizada devido as crescentes mudanças que as organizações vêm passando em razão das transformações ocorridas no ambiente externo (cenário político, econômico e social) e interno, resultantes, em especial, dos processos de globalização. Na literatura é possível encontrar diversas definições do termo competência (SANT'ANNA, 2002; FLEURY, 2002; FLEURY; FLEURY, 2004).

Para Fleury e Fleury $(2001 ; 2002 ; 2004)$, a competência pode ser conceituada como a capacidade de cada indivíduo para ter, assumir iniciativas, realizar atividades além das que estavam prescritas e ainda ser capaz de compreender, dominar novas situações de trabalho e buscar o reconhecimento e a recompensa. Deve estar alinhada à capacidade de resolver problemas, de tomar decisões rápidas e acertadas, mesmo diante do imprevisto, e ter alinhamento com os objetivos (FLEURY; FLEURY, 2001).

Competências transversais, segundo Cabral-Cardoso, Estêvão e Silva (2006, p. 37) são um "conjunto de competências pessoais gerais que são úteis e importantes no contexto do desempenho de diferentes profissões/atividades profissionais e que permitem aos indivíduos terem sucesso numa ampla variedade de tarefas e ocupações", ou seja, são os conhecimentos, habilidades, atitudes que um indivíduo pode mobilizar para desempenho de diferentes atividades profissionais. Emergem não só ao longo da vida, mas das experiências acadêmicas, como também são promovidas e estimuladas em contextos profissionais e de aprendizagem, respondendo a desafios, exigências e até mesmo aos imprevistos, estabelecendo, assim, ponte entre Universidade-Empresa (SILVA, 2016).

Os métodos de desenvolvimento das competências transversais ocorrem de três formas: 1) Integrada no currículo dos cursos (abordagem comum, mas difícil de operacionalizar); 2) Criação de módulos próprios, fora do currículo e específicos para o desenvolvimento destas competências (pouco aceito pelos estudantes); 3) Projetos desenvolvidos no ambiente de trabalho (abordagem considerada mais eficaz por parte dos empregadores) (SILVA, 2016).

Quanto à interdisciplinaridade, na visão do MEC - Ministério da Educação e Cultura (BRASIL, 1998), refere-se a uma abordagem 
epistemológica dos objetos de conhecimento, proporcionando questionamentos nos diferentes campos de conhecimento com base nos dados da realidade. Aponta a complexidade do real e a necessidade de se considerar a teia de relações entre os seus diferentes e contraditórios aspectos.

Para Lück (2001), a interdisciplinaridade promove a superação da visão restrita de mundo e a compreensão da complexidade da realidade, proporcionando conhecimento e melhor compreensão da realidade e do homem. Para que ela ocorra, é necessária a interação entre as diferentes áreas do conhecimento, num processo de comunicação de ideias, reciprocidade de conceitos, conteúdos, metodologia e objetivos. Portanto, ela envolve a integração e engajamento dos professores, num trabalho conjunto, de interação das disciplinas do currículo escolar entre si e com a realidade, superando a fragmentação do ensino.

Quanto ao aluno, deverá ser um agente ativo, comprometido, responsável, apto a planejar ações, assumir responsabilidades, tomar decisões diante dos fatos e interagir em seu meio. Cabe ao professor tornar o aluno um sujeito de sua aprendizagem. Ao ser coparticipante do processo, o discente possibilita a inclusão de saberes extracurriculares, aprenderá a planejar, a trabalhar com hipóteses e a encontrar soluções para os problemas reais (PELEIAS et al., 2011). Por consequência, transforma as questões sociais e os processos vividos e debatidos intensamente pela sociedade, numa busca incessante de soluções e alternativas para as questões sobre a vida em sociedade (BRASIL, 1998).

Desta forma, para sintonizar a universidade com uma nova ordem mundial, os paradigmas do mundo moderno e a formação científica e tecnológica dos alunos, a LDB - Lei de Diretrizes e Bases da Educação Brasileira (BRASIL, 1996) instituiu a adequação dos cursos de graduação por meio das Diretrizes Curriculares Nacionais (DCN). Em seu capítulo IV, Art. 43‥ I., afirma que a finalidade da educação é "estimular a criação cultural e o desenvolvimento do espírito científico e do pensamento reflexivo". No Título I - Da Educação, § 2ㅇ, consta que "a educação escolar deverá vincular-se ao mundo do trabalho e à prática social".

Para tanto, as DCN superam os currículos mínimos obrigatórios, permitindo uma organização curricular com relativa liberdade e flexibilidade. Essa organização deve prever: a) a permeabilidade em relação às mudanças que ocorrem no mundo científico e nos processos sociais; b) a interdisciplinaridade; c) a formação sintonizada com a realidade social; d) a perspectiva de uma educação continuada ao longo da vida; e) a articulação teoria-prática presente na dissociabilidade entre ensino, pesquisa e extensão.

Este cenário, aponta a necessidade das Instituições de Ensino Superior discutirem mais sobre a educação universitária a ser oferecida aos acadêmicos, adotar referenciais que os ajudem a perceber as várias dimensões dos fatos, em seus aspectos teóricos como práticos, diversificando e inovando as suas práticas pedagógicas e formativas para além das competências específicas.

Com objetivo de adotar uma abordagem pedagógica estratégica e inovadora, o curso de Tecnologia Gestão Empresarial da Faculdade de Tecnologia de Catanduva - FATEC Catanduva, adota a elaboração de Projetos Interdisciplinares (PIs) nos seis módulos, totalizando 360 horas de Atividade Autônoma de Projeto (AAP), integrando conjuntos de conhecimentos de determinados componentes curriculares no desenvolvimento de projetos práticos e/ou aplicados.

Tendo por base tal contexto, o objetivo desta pesquisa consiste em analisar quais competências transversais estão sendo desenvolvidas nos alunos do curso de Gestão Empresarial da FATEC Catanduva através das Atividades Autônomas de Projeto do Projeto Interdisciplinar, na construção do conhecimento através do elo entre a sala de aula e as práticas nas organizações.

\section{METODOLOGIA}

A presente pesquisa é de natureza aplicada (gerar conhecimentos para aplicação prática dirigidos a solução de problemas específicos), do tipo exploratória (proporcionar uma visão geral sobre determinado fato pouco explorado), utilizando-se de levantamento (investigação direta através de questionário para reconhecer um comportamento) e pesquisa de campo (PRODANOV; FREITAS, 2013; GIL, 2017).

Por ser uma pesquisa de opinião com participantes não identificados, esta pesquisa não foi submetida ao CEP - Comitề de Ética e Pesquisa. De acordo com o paragrafo único, item I da Resolução No. 510, de 07 de abril de 2016, fica dispensada inclusão na Plataforma Brasil e, 
portanto, não avaliada pelo CEP (CNS, 2016).

Na primeira semana de março/2018, em horário de aula, aplicou-se o Inventário de Habilidades Discentes, avaliando os Projetos Interdisciplinares (PIs) realizados no 20. semestre de 2017 em uma amostra de 227 estudantes universitários do 20. ao 60. módulo do curso de Tecnologia em Gestão Empresarial da Fatec Catanduva. $O$ total de alunos matriculados no 1 . semestre de 2018 nesses módulos foi 322, obteve-se $70 \%(N=227)$ de respondentes, cuja amostragem obtida foi por conveniência pesquisador seleciona os sujeitos que tem acesso e representam o universo (GIL, 2008). Ressalta-se que não participaram desta pesquisa alunos do 10. modulo por não terem, ainda, desenvolvido o Projeto Interdisciplinar I (PI-I), também não foi possível avaliar alunos que desenvolveram o $\mathrm{PI}$ VI, pois já haviam finalizado os estudos em dezembro/2017.

Noventa (39,6\%) dos respondentes estudavam no período da manhã e $137(60,4 \%)$ no período da noite. Cento e trinta e dois $(59,1 \%)$ estudantes eram do gênero feminino e noventa e quatro $(41,4 \%)$ do gênero masculino e apenas um estudante $(0,5 \%)$ não respondeu a essa questão. Já estavam no mercado de trabalho $73,6 \%$ dos respondentes onde $32,3 \%$ estudavam no período da manhã e $67,7 \%$ a noite.

$\mathrm{O}$ instrumento utilizado Inventário de Habilidades Discentes foi adaptado do Inventário de Práticas Docentes que Favorecem a Criatividade no Ensino Superior validado por Alencar e Fleith (2004), composto por 27 itens respondidos em uma escala de Likert (GIL, 2008) com pontuação de um a cinco pontos: discordo plenamente (1), discordo parcialmente (2), não concordo nem discordo (3), concordo parcialmente (4), concordo plenamente (5). Em sete itens foram atribuídas pontuações invertidas. Somou-se o resultado de cada item, calculou-se a média de cada item, verificando os itens com resultados elevados e baixos. Completaram o instrumento o Termo de Consentimento Livre e Esclarecido, dados sociográficos dos respondentes e instruções de como respondê-lo.

Com o instrumento foi possível avaliar 5 Competências Transversais: 1) Capacidade de aprender novos conceitos - 17 itens; 2) Iniciativa de ação e decisão - 3 itens; 3) Capacidade de Correlacionar e aplicar conhecimentos - 3 itens; 4) Resolução de problemas - 1 item; e 5) Capacidade de Relacionamento Interpessoal - 3 itens.

Para estabelecer a validade do constructo do instrumento foi verificado o coeficiente Alfa Cronbach, utilizando o Software IBM PSPP Statistics 25 , antecedido por análise exploratória dos dados, com vistas a verificar a normalidade das distribuições. $O$ índice de consistência interna ( $\alpha$ ) de toda escala foi de 0,77 , mostrando boa fidedignidade (CRONBACH, 1951; 1996).

\section{RESULTADOS}

Os Projetos Interdisciplinares da FATEC Catanduva são desenvolvidos nos seis semestres do curso de Gestão Empresarial onde em cada um há um objetivo e uma disciplina como foco principal. As demais disciplinas são envolvidas estabelecendo, também, objetivos e consequentemente ocorrendo a interdisciplinaridade.

No 19. Módulo a disciplina com foco principal é Informática Aplicada à Gestão e fazem análise descritiva da estrutura de uma organização. 20. Módulo a disciplina é Comportamento Organizacional, realizam diagnóstico de uma situação comportamental e propostas de melhoria nos processos de Gestão de Pessoas. 3o. Módulo a disciplina é Organização, Sistemas e Métodos e elaboram proposta(s) de melhorias de organização de processos gerenciais em ambiente real de uma organização. 4\%. Módulo a disciplina é Planejamento de Marketing onde os alunos elaboram um novo produto com plano de marketing e apresentam na Feira de Marketing. 50. Módulo a disciplina é Gestão de Projetos Empresariais e o objetivo: planejar, elaborar, aplicar e avaliar resultados de um projeto social. 60. Módulo a disciplina é Desenvolvimento de Negócios onde os alunos elaboraram um plano de negócio de um empreendimento.

Para Silva (2016), o desenvolvimento das competências transversais pode ocorrer de três formas: 1) de forma integrada no currículo dos cursos (difícil de operacionalizar); 2) criação de módulos próprios, fora do currículo (não é bem aceito pelos estudantes); 3) projetos desenvolvidos no ambiente de trabalho (mais eficaz por parte dos empregadores).

Na FATEC Catanduva, verifica-se que as Competências Transversais são desenvolvidas de duas formas: 1) Currículo do curso; e 2) Projetos desenvolvidos no ambiente de trabalho. No início da implantação do curso foi difícil operacionalizar essa prática pedagógica, conforme autora 
comenta, mas no estágio em que o curso se encontra, esta etapa foi superada. E os resultados da pesquisa demonstram o êxito, eficiência e aceitação dos projetos por parte dos alunos e comunidade.

Nas cinco competências transversais analisadas avaliou-se: 1) Capacidade de aprender novos conceitos: predisposição, vontade em aproximar-se e conhecer sobre um assunto, construindo o conhecimento por si mesmo; 2) Iniciativa de ação e decisão: decidir melhor maneira de agir, diante de um problema, desafio ou oportunidade, de forma rápida e com cautela (envolver aspectos racionais, mas também a intuição, a emoção, a improvisação e o acaso); 3) Capacidade de Correlacionar e aplicar conhecimentos: perceber as várias dimensões dos fatos, em seus aspectos teóricos como práticos; 4) Resolução de problemas: habilidade para enfrentar e dar resposta a uma determinada situação e/ou aplicação de uma estratégia (identificar, diagnosticar, formular, solucionar e avaliar), definida ou não, para encontrar uma solução; 5) Capacidade de Relacionamento Interpessoal: habilidade para comunicar-se com outras pessoas de forma adequada, com atenção e empatia

Todas essas cinco competências transversais analisadas foram avaliadas com pontuação média total de 100,4 (74\%) de um total máximo de 135 pontos, demonstrando que o Projeto Interdisciplinar é eficaz no desenvolvimento dessas competências transversais.

Resultado da análise de variância não mostrou diferença significativa, apenas a Competência Capacidade de Correlacionar e Aplicar Conhecimentos apresentou proximidade significativa $\left(F_{2,369}=4,222, p=0,054\right)$. O post-hoc de Tukey HSD mostrou que essa proximidade significativa é do 6 . módulo $(\overline{\mathbf{X}}=10,27 ; \mathrm{DP}=$ 1,112) para o 5‥ módulo $(\overline{\mathbf{X}}=9,16 ; \mathrm{DP}=2,282)$. Portanto, podemos dizer que o 6 . módulo demonstrou ter desenvolvido melhor a Competência Capacidade de Correlacionar e aplicar conhecimentos. Esse resultado se deve, possivelmente, por já terem desenvolvidos cinco projetos interdisciplinares e estarem no último módulo do curso.

Também foi constatada uma diferença significativa na Competência Capacidade de Correlacionar e aplicar conhecimentos na avaliação dos alunos dos períodos da manhã e noite $\left(F_{4,430}=1,225, p=0,036\right)$. Ela foi melhor avaliada pelos alunos do noturno.

\section{DISCUSSÃO}

De um modo geral, os estudantes avaliaram positivamente 0 Projetos Interdisciplinares no desenvolvimento de competências transversais. Portanto, podemos afirmar que os Projetos Interdisciplinares da FATEC Catanduva são efetivos para desenvolvimento das competências transversais.

Quanto à articulação Universidade Empresas, o PI desenvolve diversas iniciativas que promovem novas oportunidades de desenvolvimento aos estudantes, aproximando estes dois contextos: 1) os estudantes têm oportunidade de explorar e conhecer empresas no seu contexto real, por meio de visitas às empresas; 2 ) os representantes de empresas são convidados a participar em eventos e ações organizados pela Faculdade, integrando Bancas de avaliação dos PIs.

O voluntariado, também considerado uma competência transversal, embora não tenha sido analisado nesta pesquisa, é desenvolvido no $\mathrm{PI}$ do 5o. módulo, cujo Projeto Conte Comigo tem por objetivo desenvolver um produto e/ou serviço voltado à comunidade, bem como ações sociais que o contemplem, sob o viés da gestão de projetos. Como consequência o projeto irá envolver, despertar a responsabilidade, interesse e consciência em ajudar nos alunos, fortalecendo o papel comunitário e reafirmando o conceito de solidariedade em cada um que participa e colabora com o projeto. Com orientação, os estudantes têm a chance de colocar em pratica sua competência técnica e, ainda, a lidar com situações que vão contribuir com o desenvolvimento de sua formação humana. Sabe-se que o desenvolvimento de ações sociais com o auxílio do gerenciamento de projetos tem conquistados ótimos resultados e profissionais que com esse tipo de qualificação estão cada vez mais requisitados e valorizados no mercado de trabalho.

Outra política que o Centro Paula Souza oferece para os alunos que promove o desenvolvimento de competências transversais é - Programa de Mobilidade Acadêmica Internacional que oferece todo ano vagas em 19 instituições de Ensino Superior da Argentina, Bélgica, Chile, Espanha, Holanda, México e Portugal. $O$ processo de seleção leva em consideração o desempenho acadêmico. 
Para auxiliar esta prática, faz parte do currículo dos alunos em todos módulos o Inglês e, nos últimos dois módulos, o Espanhol. O aluno conhece outras culturas, analisa o entorno social estabelecendo vínculos, semelhanças e contrastes, enriquecendo sua formação.

Consequentemente, torna-se essencial pontuar o papel dos PIs para o sucesso dos estudantes da instituição, aja visto que $73,6 \%$ já estão inseridos no mercado de trabalho.

Outras competências transversais são estimuladas a serem desenvolvidas por meio do Projeto Interdisciplinar, mas não foram avaliadas nesta pesquisa: 1) Organização: habilidade para criar as condições adequadas de utilização dos recursos humanos e/ou materiais existentes, para concluir tarefas com o máximo de eficácia e eficiência; 2) Responsabilidade: capacidade de se demonstrar dedicado no trabalho, zelo por um bom funcionamento dos recursos humanos ou materiais relacionados com a tarefa de trabalho; 3) Trabalho em Equipe: habilidade para colaborar de maneira coordenada com a tarefa realizada conjuntamente por uma equipe de pessoas, com o propósito de atingir objetivos comuns; 4) Criatividade e flexibilidade: capacidade de ajustar-se a novas circunstâncias e situações, sendo capaz de mudar o modo de agir e pensar com o propósito de melhorar o resultado do trabalho; 5) Comunicação Oral: capacidade de expressar-se eficazmente em forma verbal para um grupo de pessoas e também em situações de relacionamento individual; 6) Comunicação Escrita: habilidade para expressar ideias eficazmente e transmitir informação apropriada através da palavra escrita ou outro tipo de mídia (MORENO, 2006).

\section{CONCLUSÕES}

Nos resultados obtidos pôde-se verificar que 0 Projeto Interdisciplinar possibilita desenvolver Competências Transversais nos alunos do curso de Tecnologia em Gestão Empresarial da FATEC Catanduva.

O método de ensino e aprendizagem adotado propõe projetos interdisciplinares integrados como parte da formação de seus alunos visando a participação ativa no processo de aprendizagem, interação do ensino de gestão empresarial as pesquisas, correlação do conteúdo abordado nas disciplinas, prática e responsabilidade social aplicadas por meio dos processos de extensão, ou seja, ir além, transcender os limites físicos da universidade, envolvendo-se com a comunidade, com a realidade sociocultural presente e, com isso, agregando conhecimentos práticos a respeito das mesmas.

Desta forma, a interdisciplinaridade pode contribuir para fomentar propostas e posturas metodológicas que atendam às reais necessidades dos alunos, permitindo aprendizagens significativas no contexto universitário, pois possibilitam aos acadêmicos referenciais que os ajudam a perceber as várias dimensões dos fatos, tanto em seus aspectos teóricos como práticos.

Assim, os Projetos Interdisciplinares, as atividades cooperativas, voluntariado, experiências de trabalho, extracurriculares e programas de alternância Universidade-Empresa, língua estrangeira, Programa de Mobilidade Acadêmica Internacional, possibilitam o desenvolvimento de competências transversais, aumento da autoconsciência e do sentido de oportunidade dos graduados, permitindo que consigam demonstrar as suas competências de empregabilidade num mercado de trabalho competitivo.

Nesta perspectiva, os temas transversais são fundamentos para uma formação integral e rotas estratégicas para aproximar cidadania, educação, trabalho e formação profissional. É uma forma de compreendermos e modificarmos a realidade escolar dada, é um fator de transformação, de mudança social, além de criar oportunidades para que o aluno se envolva de forma ativa na construção do seu projeto de vida, considerando as vertentes pessoais, profissionais e sociais.

Para que tudo isso ocorra é indispensável o uso de métodos pedagógicos distintos dos tradicionais. As IES deverão desenvolver estratégias inovadoras que proporcionem o desenvolvimento holístico dos estudantes, com visão integradora das competências e consequentemente do desenvolvimento de competências transversais nos estudantes.

\section{REFERÊNCIAS}

ALENCAR, E. M. L. S; FLEITH, D. S. Inventário de Práticas Docentes que Favorecem a Criatividade no Ensino Superior. Psicologia: Reflexão e Critica, Porto Alegre, v.17, n. 1, p.105-110, 2004. Disponível em: http://www.scielo.br/pdf/prc/v17n1/22310.pdf. Acesso em: 27 mai. 2017. 
https://doi.org/10.1590/S0102-

\section{$\underline{79722004000100013}$}

BRASIL. Lei no 9.394/96 de 20 de dezembro de 1996: Lei de Diretrizes e Bases da Educação Nacional. Diário Oficial da República Federativa do Brasil, Brasília, DF, n. 248, p. 27.833-27.841, dez. $\quad$ 1996. Disponível em: http://www2.camara.leg.br/legin/fed/lei/1996/le i-9394-20-dezembro-1996-362578-

publicacaooriginal-1-pl.html. Acesso em: 15 abr. 2018.

BRASIL. Parâmetros curriculares nacionais: terceiro e quarto ciclos, apresentação dos temas transversais. Brasília: MEC. 1998. Disponível em: http://portal.mec.gov.br/seb/arquivos/pdf/ttrans versais.pdf. Acesso em: 15 abr. 2018.

BRASIL. Ministério da Saúde. CNS - Conselho Nacional de saúde. Resolução no 510/2016 Dispõe sobre a pesquisa em Ciências Humanas $e$ Sociais. Brasilia: Ministério da Saúde, 2006. Disponível em: <http://conselho.saude.gov.br/resolucoes/2016/ reso510.pdf>. Acesso em: 10 ago. 2018.

CABRAL-CARDOSO, C.; ESTÊVÃO, C.V.; SILVA, P. As competências transversais dos diplomados do Ensino Superior: perspectiva dos empregadores e dos diplomados. Guimaraes: TecMinho, 2006.

CRONBACH, L. J. Coefficient alpha and the internal structure of tests, Psychometrika, n. 3, v. 16, set. 1951. Disponível em: https://pdfs.semanticscholar.org/e985/ac2e1519 03000cac310ffbc5b2cb4fbb9dd5.pdf. Acesso em: 02 jun. 2018.

CRONBACH, L. J. Fundamentos da testagem psicológica. 5. ed. Porto Alegre: Artes Médicas, 1996.

FLEURY, M. T. L. A Gestão de competências e a estratégia organizacional. In: FLEURY, M. T. L. (org.) As pessoas na Organização. São Paulo: Ed. Gente, 2002.

FLEURY, M. T. L.; FLEURY, A. Construindo o Conceito de Competência. Rev. adm. contemp., Edição Especial, v. 5, p. 183-196, 2001. Disponível em: $\quad$ http://dx.doi.org/10.1590/S141565552001000500010. Acesso em: 19 mar. 2018.
FLEURY, M. T. L.; FLEURY, A. C. C. Alinhando estratégias e competências. Rev. Adm. Empres. v. 44, n. 1, jan./mar. 2004. Disponível em: http://dx.doi.org/10.1590/S0034-

75902004000100012. Acesso em: 19 mar. 2018.

GIL, A. C. Métodos e técnicas de pesquisa social. 6. ed. São Paulo: Atlas, 2008.

GIL, A. C. Como elaborar projetos de pesquisa. 6 . ed. São Paulo: Atlas, 2017.

LÜCK, H. Pedagogia da interdisciplinaridade: Fundamentos teórico-metodológicos. Petrópolis: Vozes, 2001.

MANSILHA, S. Comunicação corporativa - textos básicos. 1. ed., Rio de Janeiro: Editora Saraiva, 2012.

MORENO, M. L. R. Evaluación, balance y formación de competencias laborales transversales: propuestas para mejorar la calidad en la formación profesional y en el mundo del trabajo. Laertes Educación: Barcelona, 2006.

PRODANOV, C. C.; FREITAS, E. C. Metodologia do trabalho cientifico: métodos e técnicas das pesquisas e do trabalho cientifico. 2. ed. Rio Grande do Sul: Universidade Feevale, 2013.

PELEIAS, I. R. et al. Interdisciplinaridade no Ensino Superior: Análise da Percepção de Professores de Controladoria em Cursos e Ciências Contábeis na Cidade de São Paulo. Avaliação, Campinas; Sorocaba, v. 16, n. 3, p. 499-532, nov. 2011.

Disponível em: http://www.scielo.br/pdf/aval/v16n3/v16n1a02.

pdf. Acesso em: 04 abr. 2018. https://doi.org/10.1590/S141440772011000300002

SANT'ANNA, A. S. Competências individuais requeridas, modernidade organizacional e satisfação no trabalho: uma análise de organização mineira sob a ótica de profissionais da área de administração. 2002. 366f. Tese (Doutorado em Administração) - Universidade Federal de Minas Gerais, Belo Horizonte, 2002.

SILVA, R. S. As Competências Transversais de Graduandos de Economia e Gestão na Interface Universidade - Mundo do Trabalho. 2016. 260f. 
Tese (Doutorado em Psicologia) - Faculdade de Psicologia e de Ciências da Educação da Universidade do Porto. Porto, maio 2016.

Submissão: 06/09/2018

Correções obrigatórias: 29/01/2019

Aceite final: 15/03/2019 